\title{
Analysis of the fecal microbiome in Kemp's ridley sea turtles Lepidochelys kempii undergoing rehabilitation
}

\author{
Mystera M. Samuelson ${ }^{1,2, *}$, Eric E. Pulis ${ }^{1,3}$, Candis Ray ${ }^{4,5}$, Covadonga R. Arias ${ }^{4}$, \\ Derrick R. Samuelson ${ }^{6}$, Erin E. Mattson ${ }^{1}$, Moby Solangi ${ }^{1}$ \\ ${ }^{1}$ The Institute for Marine Mammal Studies, Gulfport, MS 39503, USA \\ ${ }^{2}$ Department of Comparative Medicine, University of Nebraska Medical Center, Omaha, NE 68198-5875, USA \\ ${ }^{3}$ Math and Science Department, Northern State University, Aberdeen, SD 57401, USA \\ ${ }^{4}$ School of Fisheries, Aquaculture and Aquatic Sciences, Auburn University, AL 36849, USA \\ ${ }^{5}$ Harry K. Dupree Stuttgart National Aquaculture Research Center, U.S. Department of Agriculture, Stuttgart, AR 72160, USA \\ ${ }^{6}$ Department of Internal Medicine, Division of Pulmonary, Critical Care and Sleep Medicine, \\ University of Nebraska Medical Center, Omaha, NE 68198, USA
}

\begin{abstract}
The impact of the intestinal and fecal microbiome on animal health has received considerable attention in recent years and has direct implications for the veterinary and wildlife rehabilitation fields. To examine the effects of rehabilitation on the microbiome in Kemp's ridley sea turtles Lepidochelys kempii, fecal samples from 30 incidentally captured juveniles were collected during rehabilitation. Samples were analyzed to determine alpha- $(\alpha)$ and beta- $(\beta)$ diversity as well as the taxonomic abundance of the fecal microbiota during rehabilitation and in response to treatment with antibiotics. The fecal microbial communities of animals housed in rehabilitation for a 'short-term' stay (samples collected 0-9 d post-capture) were compared with 'long-term' (samples collected 10+d post-capture) and 'treated' groups (samples collected from turtles that had received antibiotic medication). Results of this study indicate that the most dominant phylum in fecal samples was Bacteroidetes (relative abundance, $45.44 \pm 5.92 \%$ [SD]), followed by Firmicutes $(26.62 \pm 1.58 \%)$, Fusobacteria $(19.49 \pm 9.07 \%)$, and Proteobacteria $(7.39 \pm 1.84 \%)$. Similarly, at the family level, Fusobacteriaceae $(28.36 \pm 17.75 \%)$, Tannerellaceae $(15.41 \pm 10.50 \%)$, Bacteroidaceae $(14.58 \pm 8.48 \%)$, and Ruminococcaceae $(11.49 \pm 3.47 \%)$ were the most abundant. Our results indicated that both antibiotic-treated and long-term rehabilitated turtles demonstrated a significant decrease in $\beta$-diversity when compared to short-term rehabilitated turtles. Our results likewise showed that the length of time turtles spent in rehabilitation was negatively correlated with $\alpha$ - and $\beta$-diversity. This study demonstrates the importance of a judicious use of antibiotics during the rehabilitation process and emphasizes the importance of limiting the length of hospital stays for sick and injured sea turtles as much as possible.
\end{abstract}

KEY WORDS: Fecal microbial communities · Kemp's ridley · Lepidochelys kempii · Gut microbiome · Bacterial diversity $\cdot$ Mississippi Sound

\section{INTRODUCTION}

The relationship between the microbiome and overall organism health has received increased attention in recent years (Carding et al. 2015). Previous

\footnotetext{
${ }^{*}$ Corresponding author: mystera.samuelson@unmc.edu
}

research has linked microbial diversity in the gut microbiome to positive health outcomes in several species, including amphibians (Bletz et al. 2013), fish (Ghanbari et al. 2015, Tarnecki et al. 2017), reptiles (Ahasan et al. 2017, Colston 2017), nonhuman pri-

(C) The authors 2020. Open Access under Creative Commons by Attribution Licence. Use, distribution and reproduction are unrestricted. Authors and original publication must be credited. 
mates (Barelli et al. 2015, Barbian et al. 2018), and humans (Gilbert et al. 2018). The microbiome impacts development, immune response, reproduction, digestion efficiency, and overall survival (Fraune \& Bosch 2010, Colston \& Jackson 2016, Price et al. 2017 ) through its interactions with various organ systems, including respiratory (Samuelson et al. 2015), digestive (Abreu \& Peek 2014), and nervous (Lyte 2013).

Kemp's ridley sea turtle Lepidochelys kempii is among the most critically endangered sea turtles in the world (Wibbels \& Bevan 2019). Research on this species has been primarily limited to data obtained during annual arribada nesting events, which predominantly occur in Mexico and Texas (Hildebrand 1963, Marquez 1994, Shaver \& Rubio 2013), and thus health data and population parameters have been informed primarily from nesting females and hatchlings. As a consequence, data regarding juvenile sea turtles are underrepresented in the literature. Opportunistic research during the rehabilitation of incidentally captured juvenile Kemp's ridley sea turtles therefore provides a unique perspective into the life history of this species (Coleman et al. 2016).

Due to the oviparous nature of the life cycle of Kemp's ridleys, nesting females do not invest energy in their offspring after depositing their eggs. However, there is evidence that eggs may be influenced by the maternal microbiome during shell development (Craven et al. 2007, Al-Bahry et al. 2009). Hatchling Kemp's ridleys navigate to surface-pelagic Sargassum communities, where they reside for their colloquially termed 'lost years' (Witherington et al. 2012). They remain in these ecosystems until they have reached the juvenile life stage $(17-27.9 \mathrm{~cm}$ straight carapace length [SCL]). Opportunistically collected fecal and esophageal samples from juveniles indicate that they primarily subsist on small marine organisms, such as hydroids and portunid crabs (Witherington et al. 2012). However, as they age (SLC 20-39.9 cm), juveniles navigate to nearshore habitats (Coleman et al. 2017) where they consume blue crabs Callinectes sapidus and spider crabs (Libinia spp.; Shaver 1991, Seney \& Musick 2005). Because of the complete lack of maternal care posthatching, hatchlings rely heavily on these early stages of foraging to foster a healthy gut microbiome (Price et al. 2017) that will facilitate the turtles' transition to the various crab species that they consume as juveniles and adults (Shaver 1991, Burke et al. 1994, Seney \& Musick 2005, Witzell \& Schmid 2005).

Due to the broad-ranging health implications of the microbiome, it is imperative that research focuses not only on its composition in healthy sea turtles, but also on how rehabilitation and veterinary treatments, including the administration of antibiotics, impact microbial communities. This is particularly true considering that gastrointestinal issues rank as a top contributor to sea turtle strandings (Flint et al. 2010). Ahasan et al. (2018) reported that green sea turtles Chelonia mydas presented with very similar bacterial communities following rehabilitation, regardless of their microbial compositions at intake. Similarly, stranded green sea turtles presented with a lower bacterial diversity than wild-caught turtles (Ahasan et al. 2017). This decreased diversity in stranded turtles may be due to the introduction of external bacteria via ingestion of fishing gear (Orós et al. 2004) and marine debris, factors which impact nutrient absorption in sea turtles (McCauley \& Bjorndal 1999). These findings underscore the importance of the hospital environment in influencing changes in the sea turtle microbiome.

The majority of research on sea turtle microbiomes has been strongly focused on green turtle cloacal (Ahasan et al. 2017, Price et al. 2017) and fecal (Campos et al. 2018) microbiomes and the intestinal microbiome of loggerhead sea turtles Caretta caretta (Abdelrhman et al. 2016). In loggerheads, the dominant microbiota found in fecal samples were Fimicutes, Bacteroidetes, and Proteobacteria-regardless of age class and overall health condition (Abdelrhman et al. 2016, Arizza et al. 2019). The prevalence of Fusobacteria, which is also prevalent in marine mammal fecal microbiomes, is likely due to a diet rich in fish (Biagi et al. 2019). The loggerhead microbiome may be impacted by hospitalization (Abdelrhman et al. 2016), although Biagi et al. (2019) suggested that the sea turtle microbiome is relatively stable throughout short-term hospital stays.

Green sea turtles differ greatly from Kemp's ridleys in both diet and habitat selection. Thus, it is likely that substantial differences exist in the composition and role of the microbiome between these species. Here we aimed to (1) summarize the fecal microbiome of immature Kemp's ridley sea turtles and (2) outline the impacts of rehabilitation on the microbiome with and without the use of antibiotics.

\section{MATERIALS AND METHODS}

\subsection{Study site}

The Institute for Marine Mammal Studies (IMMS) in Gulfport, Mississippi (USA), rescues and rehabili- 
tates sick and injured sea turtles along the Mississippi Gulf Coast, which borders the Mississippi Sound (MSS). The MSS is a 1-7 $\mathrm{m}$ deep embayment (Eleuterius 1978) spanning $2130 \mathrm{~km}^{2}$ and separated from the greater Gulf of Mexico by barrier islands (Cat, Ship, Horn, Petit Bois, and Dauphin Islands; Kjerfve 1986). The MSS harbors shallow seagrass beds (Moncreiff et al. 1992) and a thriving blue crab fishery (Rakocinski et al. 2003), making the MSS suitable habitat for juvenile sea turtles.

\subsection{Sample selection}

The majority of the turtles admitted to the hospital for rehabilitation were juvenile Kemp's ridleys, which had been incidentally captured by recreational anglers on local fishing piers but were otherwise considered to be healthy individuals (Coleman et al. 2016). This presented a unique opportunity to examine the behavior, biology, and ecology of this Critically Endangered species (Wibbels \& Bevan 2019), particularly the understudied juvenile age class, as determined by SCL.

Fecal samples were collected from 30 incidentally captured juvenile Kemp's ridley sea turtles housed at IMMS for the purposes of rehabilitation. The turtles sampled in this study were considered to be free of confounding illnesses. Subjects were treated and/or held for observation due to oral, tracheal, esophageal, and/or external injuries that were incurred as a result of incidental capture. Thus, the cause of their hospitalization was not likely to have an impact on their intestinal or fecal microbiota. Subjects were sorted into 3 groups at the time of sampling: 'shortterm' (collected 0-9 d post-capture), 'long-term' (collected $10+d$ post-capture), and 'antibiotic-treated' (collected $10+d$ post-capture from sea turtles that had been treated with the antibiotic ceftazidime while in rehabilitation; Table 1). Subjects were categorized opportunistically, as a result of the veterinarians' existing orders. The veterinary treatment, husbandry, and eventual release of the turtles was not impacted in any way by this study.

Fecal samples were collected at the completion of the turtles' respective rehabilitation periods, immediately preceding their release. The samples were collected directly from the rehabilitation pools, where turtles were housed individually. Rehabilitation pools were approximately $1 \times 0.9 \times 1 \mathrm{~m}$ in size and were filled approximately 36 " (0.91 m) deep at the time of collection. Saltwater was filtered prior to placement in the pools and was changed daily. Pools were disin- fected between fills using dilute chlorhexidine, which was allowed to sit in the drained pool for $15 \mathrm{~min}$ prior to thoroughly rinsing and refilling the pool.

Antibiotic-treated turtles received intramuscular ceftazidime, which is a third-generation cephalosporin known to be effective against Gram-positive and Gram-negative aerobic bacteria (Stamper et al. 1999). However, in reptiles, it is particularly effective against Enterobacteriaceae and Pseudomonas aeruginosa (Richards \& Brogden 1985), as well as Vibrio spp. and Aeromonas spp. (Stamper et al. 1999). Intramuscular injections of ceftazidime, as were administered in this case, have been demonstrated to be effectively absorbed and distributed throughout the body in loggerhead (Stamper et al. 1999) and Kemp's ridley sea turtles (Innis et al. 2012). For subjects included in the present study, ceftazidime was prescribed as a preventative measure for cases in which more severe injuries and/or injuries deemed by the veterinarian likely to become infected were observed at intake. Subjects suspected to have active infections, and/or subjects whose treatment included additional or alternative antibiotic treatments, were excluded from this study.

Turtles were released into the Mississippi Sound once pronounced releasable by the attending veterinarian, and the environmental conditions were deemed favorable.

\subsection{DNA extraction}

Once all fecal samples had been collected and preserved in RNAlater®, they were placed on ice and shipped to the Southeastern Cooperative Fish Parasite and Disease Laboratory (Auburn University, Alabama, USA) for DNA extraction. Upon arrival, samples were stored at $-80^{\circ} \mathrm{C}$ until processing.

Selected samples were later transferred to $-20^{\circ} \mathrm{C}$ for temporary storage and partial thawing of samples frozen in RNAlater®. Prior to DNA extraction, samples were removed from the $-20^{\circ} \mathrm{C}$ freezer, immediately placed on ice, and allowed to thaw slowly. In an effort to reduce potential problems in downstream microbial analyses from the excess salts found in RNAlater®, technicians first gently washed the fecal samples in ice cold, sterile phosphate-buffered solution 3 times. Washed fecal contents were homogenized using a handheld homogenizer and then transferred into sterile, pre-weighed, $2.0 \mathrm{ml}$ Eppendorf microcentrifuge tubes until a target weight of 160$180 \mathrm{mg}$ (or the highest available volume if less) per sample was reached. 
Table 1. Details of juvenile Kemp's ridley turtles sampled during rehabilitation, and treatment conditions (short: short-term rehabilitation, long: longterm rehabilitation, antibiotic treated: treated with ceftazidime while in rehabilitation). SCL: straight carapace length; CCL: curved carapace length. Length measurements were made notch to notch; length and weight data were taken at the time of release. Dates are given as mo/d/yr

\begin{tabular}{|lcccccc|}
\hline Sample & SCL & CCL & Weight & Release \\
ID & (cm) & (cm) & (kg) & Date & $\begin{array}{c}\text { in rehab- } \\
\text { ilitation at time } \\
\text { of sampling }\end{array}$ & Condition \\
& & & & \multicolumn{3}{c}{} \\
\hline N1 & 30.9 & 32.5 & 4.3 & $8 / 27 / 14$ & 5 & Short \\
N2 & 28.2 & 29.3 & 3.1 & $9 / 4 / 14$ & 2 & Short \\
N3 & 31.3 & 32.2 & 4.1 & $9 / 4 / 14$ & 0 & Short \\
N4 & 31.5 & 32.7 & 4.2 & $9 / 4 / 14$ & 3 & Short \\
N5 & 31.2 & 33.0 & 4.2 & $9 / 4 / 14$ & 2 & Short \\
N6 & 28.4 & 29.6 & 3.3 & $10 / 31 / 14$ & 0 & Short \\
N7 & 39.1 & 41.6 & 8.6 & $10 / 1 / 14$ & 9 & Short \\
N8 & 32.0 & 33.3 & 5.3 & $10 / 9 / 14$ & 2 & Short \\
N9 & 28.7 & 30.4 & 3.2 & $10 / 17 / 14$ & 0 & Short \\
N10 & 26.5 & 27.7 & 3.2 & $10 / 31 / 14$ & 2 & Short \\
L1 & 29.5 & 31.5 & 3.7 & $7 / 25 / 14$ & 11 & Long \\
L2 & 37.3 & 39.2 & 6.6 & $8 / 15 / 14$ & 19 & Long \\
L3 & 31.8 & 33.1 & 4.5 & $9 / 19 / 14$ & 16 & Long \\
L4 & 26.9 & 28.5 & 3.0 & $10 / 9 / 14$ & 46 & Long \\
L5 & 30.9 & 32.5 & 4.3 & $8 / 27 / 14$ & 12 & Long \\
L6 & 30.9 & 32.1 & 4.2 & $10 / 31 / 14$ & 36 & Long \\
L7 & 30.7 & 32.0 & 3.9 & $9 / 19 / 14$ & 13 & Long \\
L8 & 32.9 & 34.7 & 5.6 & $9 / 25 / 14$ & 16 & Long \\
L9 & 32.4 & 34.2 & 4.7 & $10 / 1 / 14$ & 16 & Long \\
L10 & 39.1 & 41.6 & 8.6 & $10 / 1 / 14$ & 17 & Long \\
T1 & 31.0 & 32.7 & 4.1 & $10 / 1 / 14$ & 78 & Antibiotic treated \\
T2 & 30.3 & 31.6 & 3.9 & $9 / 4 / 14$ & 43 & Antibiotic treated \\
T3 & 32.0 & 33.7 & 4.5 & $9 / 19 / 14$ & 50 & Antibiotic treated \\
T4 & 29.7 & 31.0 & 3.8 & $10 / 17 / 14$ & 88 & Antibiotic treated \\
T5 & 34.9 & 36.7 & 5.1 & $10 / 17 / 14$ & 30 & Antibiotic treated \\
T6 & 38.2 & 40.0 & 7.0 & $10 / 17 / 14$ & 51 & Antibiotic treated \\
T7 & 28.4 & 29.6 & 3.3 & $10 / 31 / 14$ & 13 & Antibiotic treated \\
T8 & 33.7 & 35.1 & 5.7 & $2 / 2 / 15$ & 41 & Antibiotic treated \\
T9 & 44.9 & 47.0 & 10.9 & $11 / 5 / 14$ & 10 & Antibiotic treated \\
T10 & 33.7 & 35.1 & 5.7 & $2 / 2 / 15$ & 21 & Antibiotic treated \\
& & & & & & \\
\hline
\end{tabular}

All DNA extractions were performed using the QIAmp® DNA Stool Mini Kit (Qiagen) according to the manufacturer's instructions, with only minor changes. Modifications to the 'Isolation of DNA from Stool for Pathogen Detection' protocol included the following: (1) the addition of ice cold, $100 \%$ ethanol to the lysate during the binding step; (2) the use of warm Buffer AE during the elution step; (3) the addition of $50 \mu \mathrm{l}$ of warmed Buffer AE directly to the spin column during elution; and (4) the extension of the final incubation period to $2 \mathrm{~min}$ at room temperature prior to elution of the DNA via centrifuging. Total DNA concentrations were then quantified using a NanoDrop ND-1000 spectrophotometer (Thermo Scientific, Nanodrop Technologies), and all samples were checked for amplification of 16S DNA prior to sending samples off for sequencing.

\subsection{DNA sequencing of the $16 \mathrm{~S}$ rRNA gene}

In total, 30 samples were submitted to MR DNA® (www.mrdnalab.com, Shallowater, Texas, USA) for PCR amplification and next-generation sequencing. Universal bacterial primers $515 \mathrm{~F}$ (5'-GTG CCA GCM GCC GCG GTA A-3') and 806R (5'-GGA CTA CHV GGG TWT CTA AT-3') with a barcode on the forward primer were used to target the 16S rRNA gene V4 variable region. The HotStarTaq Plus Master Mix Kit (Qiagen) was used to run all samples under the following PCR conditions: an initial denaturation step for $3 \mathrm{~min}$ at $94^{\circ} \mathrm{C}$ followed by 28 cycles of $94^{\circ} \mathrm{C}$ for $30 \mathrm{~s}$ (denaturing), $53^{\circ} \mathrm{C}$ for $40 \mathrm{~s}$ (annealing), and $72^{\circ} \mathrm{C}$ for $1 \mathrm{~min}$ (extension) before performing a final elongation step for $5 \mathrm{~min}$ at $72^{\circ} \mathrm{C}$. Following amplification, PCR products for all samples were run through a $2 \%$ agarose gel to verify successful amplification and relative band intensity of the target DNA. Multiple samples were pooled together and purified using calibrated Ampure $\mathrm{XP}$ beads to prepare the Illumina DNA library prior to sequencing.

\subsection{Sequence curation and analysis}

Raw sequence data were processed using $\mathrm{R}$ and the $\mathrm{R}$ packages: 'DADA2' v1.1.5, 'DECIPHER' v2.12.0, 'Phyloseq' v1.16.2, 'DESeq2' v1.20.0, and 'vegan' v2.3-5 (Anders \& Huber 2010, McMurdie \& Holmes 2012, 2015, Callahan et al. 2016, Murali et al. 2018, Oksanen 2019). Sequences were truncated to $250 \mathrm{bp}$, denoised, chimera-filtered, and clustered into sequence variants using 'DADA2.' Operational taxonomic units (OTUs) were generated in 'DADA2' by taxonomic classification of sequence variants using 'DECIPHER IDTAXA' and the 'SILVA' reference database v132. Alpha- $(\alpha)$ and beta- $(\beta)$ diversities, as well as taxonomic community assessments were analyzed via the R package 'Phyloseq.' The number of unique sequence variants in a sample ( $\alpha$-diversity) was calculated using the 'estimate richness' function in Phyloseq. Bray-Curtis dissimilarity ( $\beta$-diversity) was calculated using the 'vegdist' function in 'vegan' with raw OTU counts. Differen- 
tially abundant OTUs were determined via 'DESeq2.' All graphics were generated using 'ggplot2' (Wickham 2016).

\subsection{Statistical analysis}

We modeled $\alpha$-diversity using generalized linear models (GLMs) available within $\mathrm{R}$ (version 3.6.1). Model variables included rank time in rehabilitation, the presence of antibiotic treatment, and sequencing depth. Rank time in rehabilitation was calculated by taking the square root of the days in the rehabilitation setting to ensure a normal distribution of days. Nonmetric multidimensional scaling (NMDS) was performed on sample-wise Bray-Curtis dissimilarity distances to assess $\beta$-diversity. Significant effects of independent model covariates on NMDS clustering were inferred via permutational multivariate analysis of variance (PERMANOVA) using distance matrices within R. Pairwise comparisons were performed with corrections for multiple comparisons via false discovery rate (FDR) (Benjamini \& Hochberg 1995). A p-value $<0.05$ and an FDR q-value $<0.1$ were considered statistically significant.

\section{RESULTS}

\subsection{Time in rehabilitation and} antibiotic treatment alters the diversity of fecal microbial communities

Fecal samples from 30 incidentally captured juvenile Kemp's ridley sea turtles were sequenced and 654905 raw reads were obtained. Over $80 \%$ (536 622 total reads) of the raw reads were maintained following filtering, denoising, merging, and removing chimeras (Table 2). Utilizing the 'DADA2' pipeline, we identified 3327 unique OTUs and classified them using 'DECIPHER' at a $97 \%$ sequence similarity threshold against the SILVA reference database. Fecal samples contained between 65 and 139 OTUs, and were classified into 17 phyla, 25 classes, 33 orders, and 47 families.

Terminal microbial community structure was analyzed from fecal samples collected during rehabilitation. Neither the time a turtle spent in rehabilitation nor whether it received antibiotics resulted in marked changes to its microbial $\alpha$-diversity, as measured by Chao1, Simpson, InvSimpson, Shannon, Fisher, or abundance-based coverage estimator (ACE) diversity measurements (Table 3). While not significant, the number of observed bacterial OTUs was reduced in long-term rehabilitation and antibiotic-treated turtles when compared to turtles that underwent short-term rehabilitation (Fig. 1A).

$\beta$-diversity of the microbial communities from shotterm, long-term, and antibiotic-treated turtles was determined using sample-wise Bray-Curtis dissimilarity distances, and significant effects of independent model covariates on NMDS clustering were inferred via PERMANOVA using distance matrices. NMDS plots show that significant differences in $\beta$-diversity existed between long-term and short-term $(\mathrm{q}=$ 0.0021) turtles, as well as between short-term and
Table 2. Summary of the numbers of reads of fecal microbial communities sampled from 30 juvenile Kemp's ridley turtles. OTU: operational taxonomic unit

\begin{tabular}{|c|c|c|c|c|c|c|c|}
\hline $\begin{array}{l}\text { Sample } \\
\text { ID }\end{array}$ & $\begin{array}{l}\text { Input } \\
\text { reads }\end{array}$ & $\begin{array}{l}\text { Filtered } \\
\text { reads }\end{array}$ & $\begin{array}{l}\text { Denoised } \\
\text { forward } \\
\text { reads }\end{array}$ & $\begin{array}{l}\text { Denoised } \\
\text { reverse } \\
\text { reads }\end{array}$ & $\begin{array}{l}\text { Merged } \\
\text { reads }\end{array}$ & $\begin{array}{l}\text { Non- } \\
\text { chimera } \\
\text { reads }\end{array}$ & $\begin{array}{l}\text { Number } \\
\text { of OTUs }\end{array}$ \\
\hline L1 & 21168 & 19050 & 18834 & 18786 & 18282 & 17553 & 84 \\
\hline L2 & 23899 & 21200 & 20746 & 20707 & 19726 & 19151 & 126 \\
\hline L3 & 24531 & 21883 & 21502 & 21462 & 20622 & 20374 & 118 \\
\hline L4 & 19197 & 17148 & 16880 & 16853 & 16451 & 16063 & 100 \\
\hline L5 & 21458 & 19486 & 19093 & 19109 & 18292 & 17710 & 109 \\
\hline L6 & 16603 & 14916 & 14662 & 14647 & 14129 & 14065 & 100 \\
\hline L7 & 20104 & 18185 & 17786 & 17822 & 17241 & 17142 & 136 \\
\hline L8 & 27935 & 24947 & 24635 & 24512 & 23322 & 22793 & 105 \\
\hline L9 & 25787 & 23168 & 22765 & 22751 & 22161 & 21926 & 110 \\
\hline L10 & 19685 & 17612 & 17318 & 17303 & 16692 & 16574 & 120 \\
\hline N1 & 24574 & 22263 & 21804 & 21769 & 20502 & 19973 & 139 \\
\hline N2 & 27738 & 24840 & 24377 & 24352 & 23242 & 22961 & 171 \\
\hline N3 & 23965 & 21401 & 21047 & 21043 & 19816 & 19382 & 110 \\
\hline N4 & 21457 & 19123 & 18747 & 18688 & 17721 & 17095 & 119 \\
\hline N5 & 20258 & 18121 & 17856 & 17813 & 17002 & 16868 & 96 \\
\hline N6 & 14636 & 12943 & 12662 & 12591 & 12097 & 12097 & 134 \\
\hline N7 & 27872 & 24818 & 24323 & 24373 & 23037 & 21541 & 111 \\
\hline N8 & 24370 & 21438 & 21084 & 21115 & 20165 & 18967 & 106 \\
\hline N9 & 15059 & 13446 & 13179 & 13140 & 12533 & 12353 & 106 \\
\hline N10 & 15037 & 13278 & 13005 & 13036 & 12560 & 12211 & 97 \\
\hline $\mathrm{T} 1$ & 22972 & 20641 & 20296 & 20252 & 19450 & 19261 & 92 \\
\hline $\mathrm{T} 2$ & 23829 & 21005 & 20767 & 20741 & 19617 & 19098 & 65 \\
\hline T3 & 23492 & 20946 & 20598 & 20597 & 19330 & 18943 & 87 \\
\hline $\mathrm{T} 4$ & 20755 & 18389 & 18057 & 18045 & 17491 & 17414 & 122 \\
\hline T5 & 28621 & 25422 & 24971 & 24955 & 23585 & 22921 & 124 \\
\hline $\mathrm{T} 6$ & 19635 & 17440 & 17111 & 17075 & 16548 & 16548 & 171 \\
\hline $\mathrm{T} 7$ & 20418 & 18215 & 17890 & 17860 & 17197 & 17132 & 130 \\
\hline T8 & 25877 & 23033 & 22591 & 22548 & 21166 & 20030 & 94 \\
\hline T9 & 10156 & 8910 & 8746 & 8763 & 8462 & 8462 & 70 \\
\hline T10 & 23817 & 21605 & 21332 & 21328 & 20626 & 20014 & 75 \\
\hline
\end{tabular}


antibiotic-treated ( $\mathrm{q}=0.0025)$ individuals, as determined by PERMANOVA via 'vegan' (Fig. 1B). However, no significant difference $(\mathrm{q}=0.1586)$ was observed between long-term and antibiotic-treated turtles (Fig. 1B).

\subsection{Time in rehabilitation and antibiotic treatment changes the abundance of specific bacterial taxa}

We assessed the differences in taxonomic composition between short-term rehabilitation, long-term rehabilitation, and antibiotic-treated turtles. Specifically, the most dominant phylum in fecal samples was Bacteroidetes, with an average $( \pm \mathrm{SD})$ relative abundance of $45.44 \pm 5.92 \%$, followed by Firmicutes $(26.62 \pm 1.58 \%)$, Fusobacteria (19.49 $\pm 9.07 \%)$, and Proteobacteria $(7.39 \pm 1.84 \%)$. Less represented were Euryarchaeota, Actinobacteria, Spirochaetes, Lenti-

Table 3. Summary of $\alpha$-diversity indices of fecal microbial communities sampled from 30 juvenile Kemp's ridley turtles. OTU: operational taxonomic unit; ACE: abundance-based coverage estimator

\begin{tabular}{|c|c|c|c|c|c|c|c|}
\hline $\begin{array}{l}\text { Sample } \\
\text { ID }\end{array}$ & $\begin{array}{c}\text { Observed } \\
\text { OTUs }\end{array}$ & Chao1 & Simpson & $\begin{array}{c}\text { Inv- } \\
\text { Simpson }\end{array}$ & Shannon & Fisher & $\mathrm{ACE}$ \\
\hline L1 & 84 & 84 & 0.915 & 11.767 & 3.070 & 11.451 & 84 \\
\hline L2 & 126 & 126 & 0.933 & 15.006 & 3.593 & 18.088 & 126 \\
\hline L3 & 118 & 118 & 0.969 & 32.005 & 3.832 & 16.586 & 118 \\
\hline L4 & 100 & 100 & 0.926 & 13.434 & 3.376 & 14.224 & 100 \\
\hline L5 & 109 & 109 & 0.931 & 14.419 & 3.375 & 15.475 & 109 \\
\hline L6 & 100 & 100 & 0.918 & 12.188 & 3.312 & 14.545 & 100 \\
\hline L7 & 136 & 136 & 0.977 & 42.920 & 4.121 & 20.157 & 136 \\
\hline L8 & 105 & 105 & 0.928 & 13.814 & 3.323 & 14.228 & 105 \\
\hline L9 & 110 & 110 & 0.956 & 22.487 & 3.560 & 15.108 & 110 \\
\hline L10 & 120 & 120 & 0.947 & 18.725 & 3.651 & 17.508 & 120 \\
\hline N1 & 139 & 139 & 0.941 & 16.821 & 3.539 & 20.144 & 139 \\
\hline N2 & 171 & 171 & 0.949 & 19.771 & 3.882 & 25.070 & 171 \\
\hline N3 & 110 & 110 & 0.883 & 8.574 & 3.044 & 15.411 & 110 \\
\hline N4 & 119 & 119 & 0.945 & 18.063 & 3.468 & 17.247 & 119 \\
\hline N5 & 96 & 96 & 0.897 & 9.673 & 3.030 & 13.456 & 96 \\
\hline N6 & 134 & 134 & 0.964 & 28.155 & 3.986 & 21.090 & 134 \\
\hline N7 & 111 & 111 & 0.929 & 14.101 & 3.327 & 15.311 & 111 \\
\hline N8 & 106 & 106 & 0.852 & 6.744 & 2.771 & 14.813 & 106 \\
\hline N9 & 106 & 106 & 0.783 & 4.618 & 2.595 & 15.928 & 106 \\
\hline N10 & 97 & 97 & 0.878 & 8.206 & 3.151 & 14.380 & 97 \\
\hline T1 & 92 & 92 & 0.933 & 14.849 & 3.246 & 12.538 & 92 \\
\hline $\mathrm{T} 2$ & 65 & 65 & 0.880 & 8.314 & 2.669 & 8.411 & 65 \\
\hline T3 & 87 & 87 & 0.843 & 6.386 & 2.784 & 11.784 & 87 \\
\hline $\mathrm{T} 4$ & 122 & 122 & 0.964 & 27.924 & 3.860 & 17.701 & 122 \\
\hline T5 & 124 & 124 & 0.922 & 12.879 & 3.271 & 17.238 & 124 \\
\hline T6 & 171 & 171 & 0.950 & 20.083 & 3.820 & 26.570 & 171 \\
\hline $\mathrm{T} 7$ & 130 & 130 & 0.958 & 23.689 & 3.723 & 19.120 & 130 \\
\hline T8 & 94 & 94 & 0.956 & 22.549 & 3.523 & 12.775 & 94 \\
\hline T9 & 70 & 70 & 0.794 & 4.863 & 2.173 & 10.451 & 70 \\
\hline $\mathrm{T} 10$ & 75 & 75 & 0.806 & 5.148 & 2.313 & 9.846 & 75 \\
\hline
\end{tabular}

sphaerae, Epsilonbacteraeota, and Verrucomicrobia, (ranging from $0.311-0.096 \%$ relative abundance, respectively). Similarly, at the family level, Fusobacteriaceae $(28.36 \pm 17.75 \%)$, Tannerellaceae (15.41 \pm $10.50 \%)$, Bacteroidaceae $(14.58 \pm 8.48 \%)$, and Ruminococcaceae $(11.49 \pm 3.47 \%)$ were the most abundant. Fig. 2A shows the breakdown of the relative abundance of taxa at the genus level in short-term rehabilitation, long-term rehabilitation, and antibiotictreated turtles.

Comparisons between the microbial communities in each group demonstrated significant changes in the relative abundance of specific OTUs as determined by 'DESeq2.' Specifically, 8 OTUs were more abundant in long-term rehabilitation turtles than short-term turtles, while 8 OTUs were more abundant in short-term rehabilitation turtles when compared to long-term turtles (Fig. 2B). Similarly, 8 OTUs were more abundant in antibiotic-treated turtles compared to short-term turtles, while 7 OTUs were more abundant in short-term rehabilitation turtles than antibiotic-treated turtles (Fig. 2C). Finally, 1 OTU was more abundant in long-term rehabilitation turtles when compared to antibiotic-treated turtles, and 5 OTUs were more abundant in antibiotictreated turtles than long-term rehabilitation turtles (Fig. 2D).

\subsection{Days in rehabilitation correlate with loss of $\alpha$-diversity and changes in $\beta$-diversity}

We determined that the number of days that a turtle spent in rehabilitation had a negative association with $\alpha$-diversity ( $r h o=-0.2417 \mathrm{p}=0.198$ ), as determined by multiple general linear regression (Fig. 3A). Model covariables included antibiotic treatment and sequencing depth. $\beta$-diversity was also significantly associated with days in rehabilitation ( $p=0.0001$, PERMANOVA) (Fig. 3B).

\section{DISCUSSION}

Both the structure of microbial communities and the taxonomic abundance of the fecal microbiota were sig- 

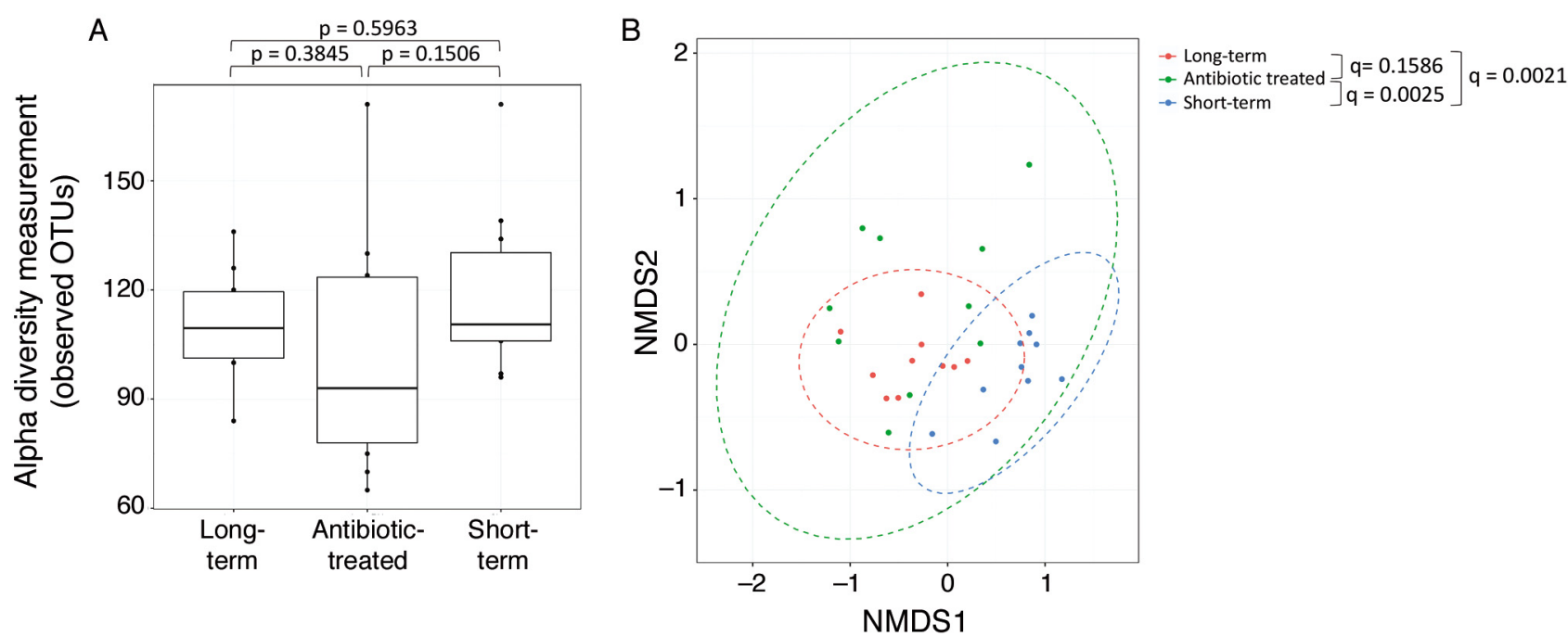

Fig. 1. (A) $\alpha$-diversity (determined by multiple general linear regression) and (B) $\beta$-diversity (determined by PERMANOVA in R) of fecal microbial communities from Kemp's ridley sea turtles in rehabilitation (short-term, long-term, and antibiotictreated). In (B), pairwise comparisons were performed with corrections for multiple comparisons via false discovery rate (FDR), and significant differences (FDR q-value $<0.05$ ) were observed between long-term and short-term, as well as between shortterm and antibiotic-treated animals

nificantly affected by the length of stay in rehabilitation, as well as the use of antibiotics. $\alpha$-diversity and $\beta$-diversity metrics were also correlated with the length of stay in rehabilitation, when accounting for antibiotic treatment. As the relationship between the fecal microbiome and its impact on an animal's overall health is poorly understood, additional research is required to fully understand the implications of these changes on an individual's long-term health outcomes.

The characterization of the fecal microbiome for sea turtles worldwide is an area of growing interest. To our knowledge, our study is the first to examine the fecal microbiome of Kemp's ridley sea turtles and the influence of rehabilitation on the microbiome of this species. Our results demonstrate that the most dominant phylum in fecal samples from Kemp's ridley sea turtles were Bacteroidetes, Firmicutes, Fusobacteria, and Proteobacteria. This coincides with findings from loggerheads (Abdelrhman et al. 2016, Arizza et al. 2019), which may be due at least in part to an overlap in dietary preferences and habitat selection between the 2 species. In addition, the fecal microbiota was significantly affected by the length of stay in rehabilitation, as well as by the use of antibiotics. Specifically, we observed changes in several diversity metrics, as well as a significant reduction in the abundance of Bilophila, Butyricomonas, Eubacterium, Macellibacteroides Parabacteroides, Paraeggerthella, Tyzzerella, and Vibrio in long-term re- habilitated turtles when compared to short-term rehabilitated turtles. These results are similar to results seen in green sea turtles, where Bilophila were enriched in pre-rehabilitation turtles compared to posthospitalized turtles. Further, our results revealed that long-term or treated turtles exhibited a significant increase in Moritella and Photobacterium (Proteobacteria) compared to short-term turtles.

We found that turtles undergoing long-term rehabilitative care and turtles treated with antibiotics demonstrated a significant decrease in the abundance of several genera that could have potential health implications. For example, Butyricomonas and Eubacterium produce butyrate, a short-chain fatty acid essential for intestinal health (Amato et al. 2013). Additionally, increased levels of Bilophila in short-term turtles could indicate that these organisms are important for normal gut physiology and nutrition, as suggested for green turtles (Ahasan et al. 2018). Converse to what was observed in green turtles (Ahasan et al. 2017), we found the genus Vibrio to be enriched in short-term rehabilitated turtles compared to long-term or treated turtles. However, Vibrio could have varying health implications depending upon the species of bacteria. For example, $V$. harveyi, V. owensii, and V. parahaemolyticus can indicate an opportunistic infection (Ahasan et al. 2018), while other species common to the microbiome of marine crustaceans and mollusks ( $V$. xuii and $V$. pomeroyi, for example) have been found to be 

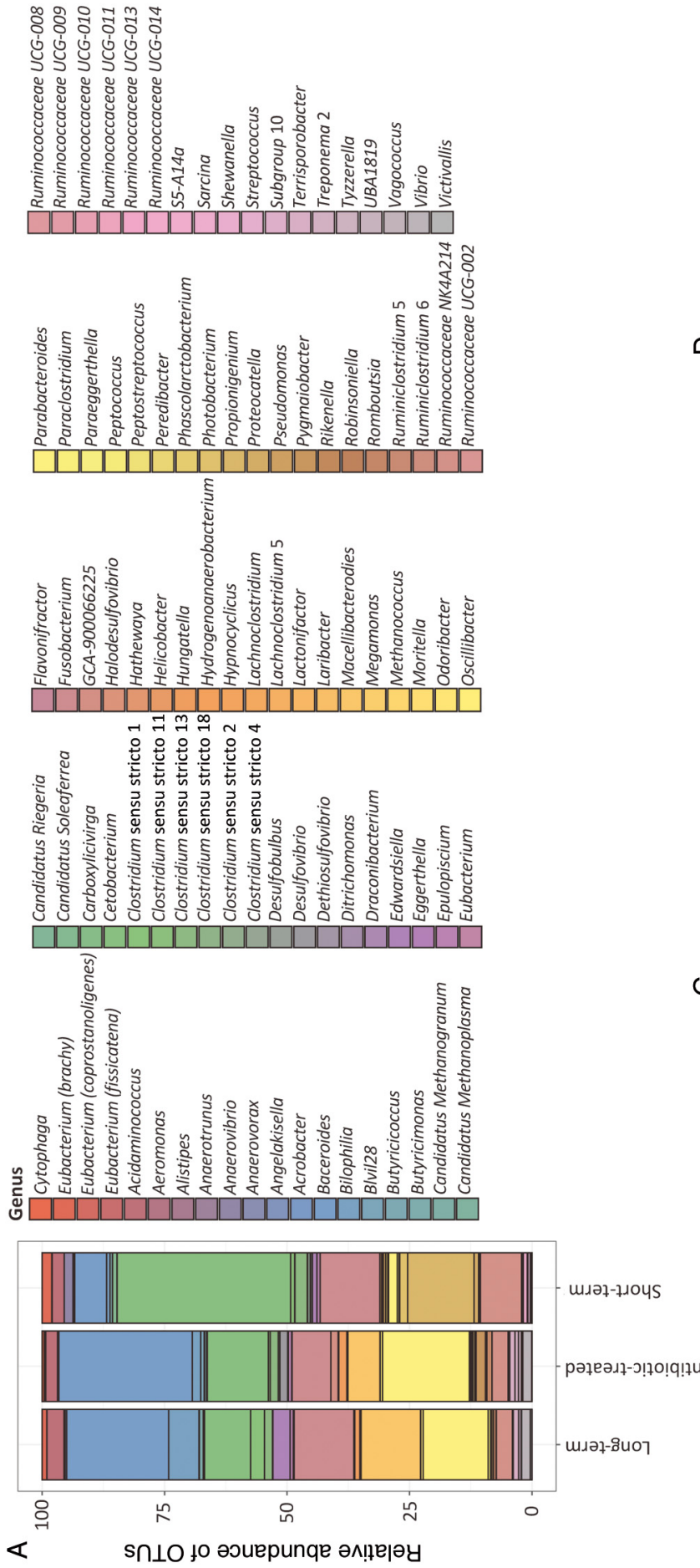

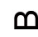


A

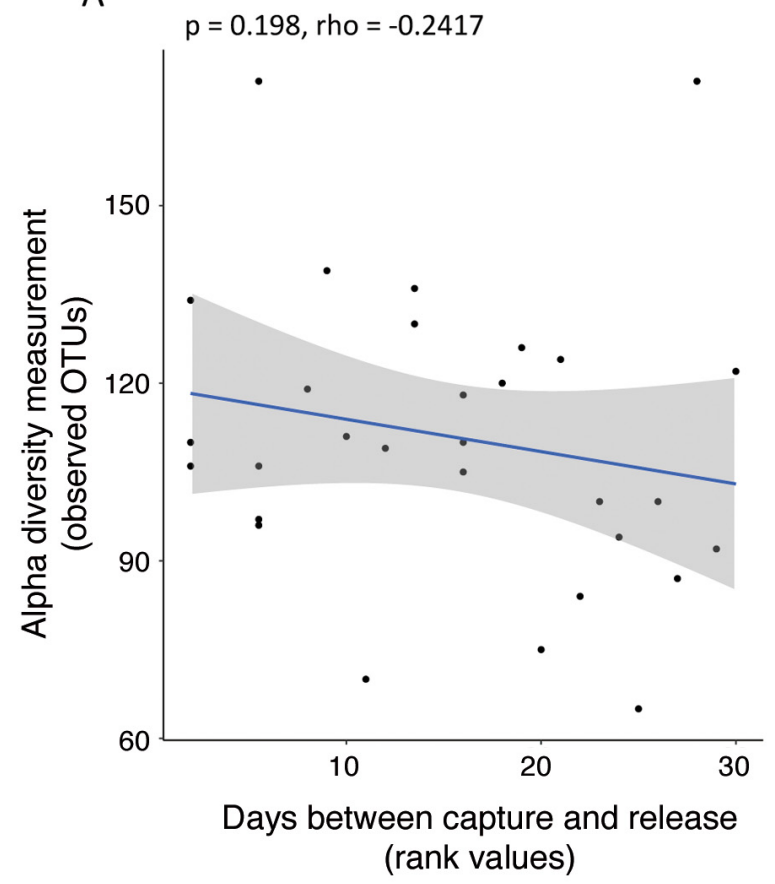

B

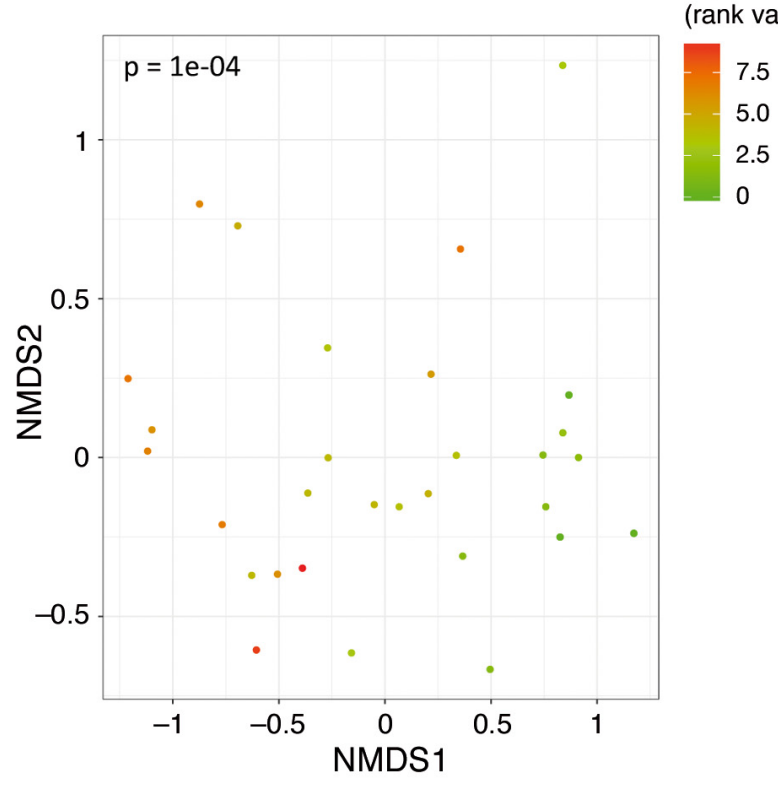

Days between capture and release (rank values) 
Additionally, the role of the microbiome must be considered in species preservation plans that involve managed zoological or rehabilitative care, given that dysbiosis, a divergence from the normal microbial community, is strongly associated with the development of disease. Thus, caregivers and veterinarians should consider the addition of pre- and probiotics to daily care regimens, as well as increasing diet diversity (West et al. 2019). Additionally, it should be noted that both habitat degradation and climate change have been demonstrated to impact the structure and function of the microbiome in a variety of species (Apprill 2017, West et al. 2019). Therefore, it is critical that evaluations of the Kemp's ridley microbiome be repeated over time as a method for monitoring long-term changes in sea turtle and environmental health.

Acknowledgements. We thank the Institute for Marine Mammal Studies for funding this work, as well as the interns and staff who assisted in data collection for this project.

\section{LITERATURE CITED}

Abdelrhman KFA, Bacci G, Mancusi C, Mengoni A, Serena F, Ugolini A (2016) A first insight into the gut microbiota of the sea turtle Caretta caretta. Front Microbiol 7:1060

Abreu MT, Peek RM Jr (2014) Gastrointestinal malignancy and the microbiome. Gastroenterology 146:1534-1546

Ahasan MS, Waltzek TB, Huerlimann R, Ariel E (2017) Fecal bacterial communities of wild-captured and stranded green turtles (Chelonia mydas) on the Great Barrier Reef. FEMS Microbiol Ecol 93:fix139

Ahasan MS, Waltzek TB, Huerlimann R, Ariel E (2018) Comparative analysis of gut bacterial communities of green turtles (Chelonia mydas) pre-hospitalization and postrehabilitation by high-throughput sequencing of bacterial 16S rRNA gene. Microbiol Res 207:91-99

Al-Bahry S, Mahmoud I, Elshafie A, Al-Harthy A, Al-Ghafri S, Al-Amri I, Alkindi A (2009) Bacterial flora and antibiotic resistance from eggs of green turtles Chelonia mydas: an indication of polluted effluents. Mar Pollut Bull 58:720-725

Amato KR, Yeoman CJ, Kent A, Righini N and others (2013) Habitat degradation impacts black howler monkey (Alouatta pigra) gastrointestinal microbiomes. ISME J 7: 1344-1353

Anders S, Huber W (2010) Differential expression analysis for sequence count data. Genome Biol 11:R106

Apprill A (2017) Marine animal microbiomes: toward understanding host-microbiome interactions in a changing ocean. Front Mar Sci 4:222

Arizza V, Vecchioni L, Caracappa S, Sciurba G and others (2019) New insights into the gut microbiome in loggerhead sea turtles Caretta caretta stranded on the Mediterranean coast. PLOS ONE 14:e0220329

Barbian HJ, Li Y, Ramirez M, Klase Z and others (2018) Destabilization of the gut microbiome marks the endstage of simian immunodeficiency virus infection in wild chimpanzees. Am J Primatol 80:e22515
Barelli C, Albanese D, Donati C, Pindo M and others (2015) Habitat fragmentation is associated to gut microbiota diversity of an endangered primate: implications for conservation. Sci Rep 5:14862

Benjamini Y, Hochberg Y (1995) Controlling the false discovery rate: a practical and powerful approach to multiple testing. J R Stat Soc B (Methodological) 57:289-300

Biagi E, D'Amico F, Soverini M, Angelini V and others (2019) Faecal bacterial communities from Mediterranean loggerhead sea turtles (Caretta caretta). Environ Microbiol Rep 11:361-371

* Bletz MC, Loudon AH, Becker MH, Bell SC, Woodhams DC, Minbiole KP, Harris RN (2013) Mitigating amphibian chytridiomycosis with bioaugmentation: characteristics of effective probiotics and strategies for their selection and use. Ecol Lett 16:807-820

Burke VJ, Morreale SJ, Standora EA (1994) Diet of the Kemp's ridley sea turtle, Lepidochelys kempii, in New York waters. Fish Bull 92:26-32

* Callahan BJ, Sankaran K, Fukuyama JA, McMurdie PJ, Holmes SP (2016) Bioconductor workflow for microbiome data analysis: from raw reads to community analyses. F1000Research 5:1492

* Campos P, Guivernau M, Prenafeta-Boldú FX, Cardona L (2018) Fast acquisition of a polysaccharide fermenting gut microbiome by juvenile green turtles Chelonia mydas after settlement in coastal habitats. Microbiome 6:69

Carding S, Verbeke K, Vipond DT, Corfe BM, Owen LJ (2015) Dysbiosis of the gut microbiota in disease. Microb Ecol Health Dis 26:26191

Coleman AT, Pulis EE, Pitchford JL, Crocker K and others (2016) Population ecology and rehabilitation of incidentally captured Kemp's ridley sea turtles (Lepidochelys kempii) in the Mississippi Sound, USA. Herpetol Conserv Biol 11:253-264

Coleman AT, Pitchford JL, Bailey H, Solangi M (2017) Seasonal movements of immature Kemp's ridley sea turtles (Lepidochelys kempii) in the northern Gulf of Mexico. Aquat Conserv 27:253-267

Colston TJ (2017) Gut microbiome transmission in lizards. Mol Ecol 26:972-974

* Colston TJ, Jackson CR (2016) Microbiome evolution along divergent branches of the vertebrate tree of life: what is known and unknown. Mol Ecol 25:3776-3800

Craven KS, Awong-Taylor J, Griffiths L, Bass C, Muscarella $M$ (2007) Identification of bacterial isolates from unhatched loggerhead (Caretta caretta) sea turtle eggs in Georgia, USA. Mar Turtle Newsl 115:9-11

Eleuterius CK (1978) Geographical definition of Mississippi Sound. Gulf Res Rep 6:179-181

Flint M, Patterson-Kane JC, Limpus CJ, Mills PC (2010) Health surveillance of stranded green turtles in Southern Queensland, Australia (2006-2009): an epidemiological analysis of causes of disease and mortality. EcoHealth 7: 135-145

Fraune S, Bosch TCG (2010) Why bacteria matter in animal development and evolution. BioEssays 32:571-580

Ghanbari M, Kneifel W, Domig KJ (2015) A new view of the fish gut microbiome: advances from next-generation sequencing. Aquaculture 448:464-475

Gilbert JA, Blaser MJ, Caporaso JG, Jansson JK, Lynch SV, Knight R (2018) Current understanding of the human microbiome. Nat Med 24:392-400

Hildebrand HH (1963) Hallazgo del area de anidacion de la Tortuga marina 'lora,' Lepidochelys kempi (Garman), en 
la costa occidental del golfo de Mexico (Rept., Chel). Ciencia 22:105-112

Innis CJ, Ceresia ML, Merigo C, Weber ES III, Papich MG (2012) Single-dose pharmacokinetics of ceftazidime and fluconazole during concurrent clinical use in coldstunned Kemp's ridley turtles (Lepidochelys kempii). J Vet Pharmacol Ther 35:82-89

Kjerfve B (1986) Comparative oceanography of coastal lagoons. In: Wolfe DA (ed) Estuarine variability, Vol 32. Academic Press, New York, NY, p 63-81

Lyte M (2013) Microbial endocrinology in the microbiomegut-brain axis: how bacterial production and utilization of neurochemicals influence behavior. PLOS Pathog 9: e1003726

Marquez MR (1994) Synopsis of biological data on the Kemp's ridley turtle, Lepidochelys kempi (Garman, 1880). NOAA Tech Memo NMFS-SEFSC-343

McCauley SJ, Bjorndal KA (1999) Conservation implications of dietary dilution from debris ingestion: sublethal effects in post-hatchling loggerhead sea turtles. Conserv Biol 13:925-929

McMurdie PJ, Holmes S (2012) Phyloseq: a bioconductor package for handling and analysis of high-throughput phylogenetic sequence data. Biocomputing 2012:235-246

McMurdie PJ, Holmes S (2015) Shiny-phyloseq: Web application for interactive microbiome analysis with provenance tracking. Bioinformatics 31:282-283

Moncreiff CA, Sullivan MJ, Daehnick AE (1992) Primary production dynamics in seagrass beds of Mississippi Sound: the contributions of seagrass, epiphytic algae, sand microflora, and phytoplankton. Mar Ecol Prog Ser 87:161-171

Murali A, Bhargava A, Wright ES (2018) IDTAXA: a novel approach for accurate taxonomic classification of microbiome sequences. Microbiome 6:140

Oksanen J, Blanchet FG, Friendly M, Kindt R and others (2019) Package 'vegan'. Community ecology package. https://cran.r-project.org/web/packages/vegan/vegan.pdf

Orós J, Calabuig P, Déniz S (2004) Digestive pathology of sea turtles stranded in the Canary Islands between 1993 and 2001. Vet Rec 155:169-174

Price JT, Paladino FV, Lamont MM, Witherington BE, Bates ST, Soule T (2017) Characterization of the juvenile green turtle (Chelonia mydas) microbiome throughout an ontogenetic shift from pelagic to neritic habitats. PLOS ONE 12:e0177642

Editorial responsibility: Sandra Hochscheid, Napoli, Italy
Rakocinski CF, Perry HM, Abney MA, Larsen KM (2003) Soft-sediment recruitment dynamics of early blue crab stages in Mississippi Sound. Bull Mar Sci 72:393-408

Richards DM, Brogden RN (1985) Ceftazidime. Drugs 29: 105-161

* Romalde JL, Diéguez AL, Lasa A, Balboa S (2014) New Vibrio species associated to molluscan microbiota: a review. Front Microbiol 4:413

* Samuelson DR, Welsh DA, Shellito JE (2015) Regulation of lung immunity and host defense by the intestinal microbiota. Front Microbiol 6:1085

Seney EE, Musick JA (2005) Diet analysis of Kemp's ridley sea turtles (Lepidochelys kempii) in Virginia. Chelonian Conserv Biol 4:864-871

Shaver DJ (1991) Feeding ecology of wild and head-started Kemp's ridley sea turtles in South Texas waters. J Herpetol 25:327-334

Shaver DJ, Hart KM, Fujisaki I, Rubio C and others (2013) Foraging area fidelity for Kemp's ridleys in the Gulf of Mexico. Ecol Evol 3:2002-2012

Stamper MA, Papich MG, Lewbart GA, May SB, Plummer DD, Stoskopf MK (1999) Pharmacokinetics of ceftazidime in loggerhead sea turtles (Caretta caretta) after single intravenous and intramuscular injections. J Zoo Wildl Med 30:32-35

Tarnecki AM, Burgos FA, Ray CL, Arias CR (2017) Fish intestinal microbiome: diversity and symbiosis unraveled by metagenomics. J Appl Microbiol 123:2-17

*West AG, Waite DW, Deines P, Bourne DG, Digby A, McKenzie VJ, Taylor MW (2019) The microbiome in threatened species conservation. Biol Conserv 229: 85-98

Wibbels T, Bevan E (2019) Lepidochelys kempii (errata version published in 2019). The IUCN Red List of Threatened Species 2019: e.T11533A155057916. https://dx.doi.org/ 10.2305/IUCN.UK.2019-2.RLTS.T11533A155057916.en.

Wickham H (2016) ggplot2: Elegant graphics for data analysis. Springer-Verlag, New York, NY

*Witherington B, Hirama S, Hardy R (2012) Young sea turtles of the pelagic Sargassum-dominated drift community: habitat use, population density, and threats. Mar Ecol Prog Ser 463:1-22

Witzell WN, Schmid JR (2005) Diet of immature Kemp's ridley turtles (Lepidochelys kempi) from Gullivan Bay, Ten Thousand Islands, Southwest Florida. Bull Mar Sci 77: 191-199

Submitted: October 14, 2019; Accepted: May 28, 2020

Proofs received from author(s): September 1, 2020 